\title{
Ossification process involving the human thoracic ligamentum flavum: role of transcription factors
}

\author{
Kenzo Uchida ${ }^{1 \dagger}$, Takafumi Yayama ${ }^{1{ }^{*}}$, Hong-Xin Cai ${ }^{1,2}$, Hideaki Nakajima', Daisuke Sugita ${ }^{1}$, \\ Alexander Rodríguez Guerrero ${ }^{1,3}$, Shigeru Kobayashi', Ai Yoshida', Ke-Bing Chen ${ }^{1,4}$ and Hisatoshi Baba'
}

\begin{abstract}
Introduction: Ossification of the ligamentum flavum (OLF) of the spine is associated with serious neurologic compromise, but the pathomechanism of this process remains unclear. The objective of this study was to investigate the pathomechanism of the ossification process, including the roles of various transcriptional factors in the ossification of human thoracic ligamentum flavum.
\end{abstract}

Methods: Sections of the thoracic ligamentum flavum were obtained from 31 patients with OLF who underwent posterior thoracic decompression, and from six control patients free of OLF. Cultured ligamentum flavum cells $(n=$ 6 , each) were examined with real-time reverse transcription-polymerase chain reaction (RT-PCR) analysis for Sry-type high-mobility group box 9 (Sox9), runt-related transcription factor 2 (Runx2), muscle segment homeobox 2 (Msx2), Osterix, distal-less homeobox 5 (Dlx5), and AP-1. The harvested sections were examined with hematoxylin-eosin, the terminal deoxynucleotidyl transferase-mediated dUTP-biotin nick end-labeling (TUNEL) method, and immunohistochemistry for the transcriptional factors.

Results: Compared with the control, the OLF showed disorganization of the elastic fiber bundles and abundant hypertrophic chondrocytes in the ossification front. TUNEL-positive chondrocytes were found near the ossified plaques. The mRNA expression levels of Sox9, Runx2, Msx2, and AP-1 in cultured cells from the ligamentum flavum of OLF patients were significantly different from those of the control. OLF samples were strongly immunoreactive to Sox9, Runx2, and Msx2 at proliferating chondrocytes in the fibrocartilage area. Hypertrophic chondrocytes were positive for Runx2, Osterix, Dl×5, and AP-1.

Conclusions: The ossification process in OLF seems to involve chondrocyte differentiation under the unique expression of transcriptional factors. Accumulation of hypertrophic chondrocytes was evident around the calcified area at the ossification front, and we suggest that the differentiation of these cells seems to be concerned with the ossification process.

\section{Introduction}

Various pathologic conditions are known to result in ossification of the spinal ligament with subsequent neurologic compromise. Ossification of the ligamentum flavum (OLF) is an isolated form of spinal column ossification but also occurs in association with diffuse idiopathic skeletal hyperostosis, ankylosing spondylitis, and metabolic diseases such as Paget disease, hypoparathyroidism, and X-linked hypophosphatemia [1-5]. This

\footnotetext{
* Correspondence: yayama@u-fukui.ac.jp

+ Contributed equally

'Department of Orthopaedics and Rehabilitation Medicine, Faculty of

Medical Sciences, Fukui University, Eiheiji, Fukui 910-1193, Japan

Full list of author information is available at the end of the article
}

clinical entity has been reported almost exclusively in northern East Asian countries, although it has been investigated in other regions, including southern China, India, the Middle East, and Caribbean Islands [6-8]. Although recent advances in radiologic and electrophysiological techniques allow early diagnosis of OLF $[9,10]$, little is known about the spatial progress within the spinal canal, and no standardized treatment is known for OLF.

Several studies have described the possible roles of mechanical, genetic, metabolic, and cell biologic factors in the development and progression of OLF [11-15]. From a histopathologic point of view, enchondral ossification contributes to bone formation in the spinal 
ligaments [16]. The ossification fronts exist between the ossified plaque and the non-ossified fibrous area; they form a multiple-layer structure that includes the fibrocartilage layer, calcification front, calcified-cartilage layer, and ossified region. In our previous studies, we observed disordered orientation of the elastic fibers and expansion of the cartilaginous area in the early stages of ossification in the twy/twy mouse, which is known to develop spontaneous spinal ligament ossification [11,17]. In human samples of the ossified spinal ligament, the ossification front includes proliferating small blood vessels and clusters of hypertrophic chondrocytes producing various forms of collagen (such as collagen type II or type X), particularly around the calcification front $[18,19]$. Thus, we considered that these chondrocytes are involved in the progression of OLF, although these pathologic processes have not yet been elucidated.

The present study is an extension of our previous studies [11,17-19] and was designed to determine the ossification process in human OLF samples. Specifically, we focused on the expression and localization of the transcriptional factors that modulate the properties of fibroblasts-like cells and chondrocytes at the ossification front during the process of ossification.

\section{Materials and methods Patient population}

A total of 31 patients who presented with progressive symptoms and signs of myelopathy and radiologic evidence of OLF (18 men, 13 women; mean age at surgery, 69.0 years; range, 52 to 86 years) underwent posterior decompressive surgery for thoracic OLF between 2001 and 2009. Samples of non-ossified ligamentum flavum obtained from six patients (three men and three women; mean age, 69.8 years; range, 60 to 81 years), who underwent posterior surgery for fracture or disc herniation in the thoracic spine, served as the controls. None of the patients had evidence of congenital bone or joint disorders or musculoligamentous tissue abnormalities. None of the patients was positive for rheumatoid factor, had hyperparathyroidism, or was taking glucocorticoids or bisphosphonate.

Patients had a variable degree of OLF-related spinalcord impingement posteriorly and posterolaterally (Figure $1 \mathrm{a}, \mathrm{b}$ ). The lesion was categorized as lateral (six cases), extended (seven cases), enlarged (seven cases), fused (six cases), or tuberous (five cases) subtype, based on examination of computed tomography (CT) images taken at the level suspected to be responsible for the myelopathy and the proposed CT classification of thoracic OLF [20,21].

All patients underwent posterior decompressive surgeries: one-level decompression in 19 patients, two-level decompression in 10 patients, and three-level

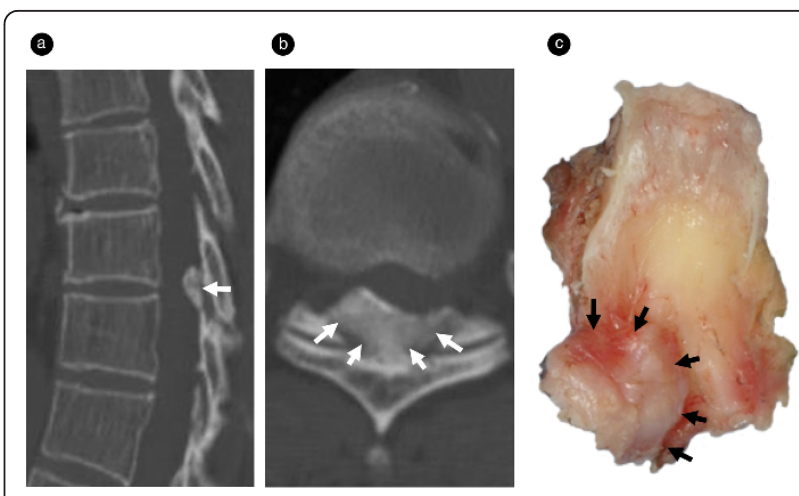

Figure 1 Representative case of tuberous type OLF. Sagittal (a) and axial (b) CT images obtained in a 72-year-old woman with T1112 OLF. Note the fusing of the ossified plaque at midline and the progression of this process into the spinal canal. The resected sample (c) contains a hard mass from dura mater aspect (arrow, ossification). $C T$, computed tomography; OLF, ossification of the ligamentum flavum.

decompression in two patients. A level-specific diagnosis was made based on neurologic signs, CT findings, spinal cord-evoked potentials, and magnetic resonance imaging (MRI: 1.5-Tesla Signa, General Electric, Milwaukee, WI, USA).

The applied surgical technique was described in detail in our previous publication [19]. The OLF sample was obtained through a posterior midline approach followed by exposure of the vertebral laminae and ligamentum flavum. The spinous processes and cortices of the laminae near the OLF lesion were cut or resected, by using either a high-speed surgical drill or a microKerrison rongeur (with a 2 -mm blade and 1-mm thickness), under a direct surgical microscope (OPM 16CFC; Carl-Zeiss, Oberkochen, Germany). Because the OLF lesion often extended laterally, just medial to the facet joint, approximately the medial one third of the facet joint at the affected vertebral level(s) was resected, followed by cutting the inner cortex of the far-lateral site of the lamina. The OLF lesion was then isolated and floated like an "island" on the dura mater vis a tergo. At that stage, a pair of epidural electrodes (Unique Medical, Tokyo, Japan) was positioned approximately 4 to $6 \mathrm{~cm}$ away from the OLF lesion, proximally and distally, for spinal cord monitoring [9]. A pair of fine-tip skin-hooks was then applied to the sides of OLF lesion to lift carefully the ossified plaque dorsally away from the dura mater, before it was finally resected. The dura mater was also sometimes resected even when ossified, but care was taken to preserve the arachnoid membrane.

A written informed consent was obtained from each patient, and the study protocol strictly followed the Human Ethics Review Committee of our University. 


\section{Cell culture}

Ligament specimens were harvested under aseptic conditions during surgery from six patients (three men and three women; mean age at surgery, 71.0 years; range, 59 to 84 years; four fused type and two tuberous type on CT classification) for cell culture. Samples of non-ossified ligamentum flavum (three men, three women; mean age, 69.8 years; range, 60 to 81 years) were obtained from six patients who underwent thoracic posterior surgeries and served as the control. The tissues surrounding the ligaments were removed carefully under a dissecting microscope, and the ligaments were extirpated carefully from the not-ossified areas to avoid contamination with osteogenic cells. The collected ligaments were minced into approximately $0.5-\mathrm{mm}^{3}$ pieces and then plated onto $25-\mathrm{mm}^{2}$ culture dishes and maintained in Dulbecco modified Eagle medium supplemented with $10 \%$ fetal bovine serum, $100 \mathrm{unit} / \mathrm{ml}$ penicillin G sodium, and $100 \mu \mathrm{g} / \mathrm{ml}$ streptomycin sulfate in a humidified atmosphere of $95 \%$ air and $5 \% \mathrm{CO}_{2}$ at $37^{\circ}$ C. At confluence, the cells were harvested from the dishes with $0.02 \%$ ethylenediaminetetraacetic acid (EDTA) and $0.05 \%$ trypsin for further passages. The cultured cells were characterized at the third passage. Samples of six control specimens were cultured in a similar fashion.

Real-time reverse transcription-polymerase chain reaction (RT-PCR) analysis

Real-time RT-PCR was used for semiquantitative analysis of the relative mRNA expression levels of transcriptional factors (repeated 3 times for each sample), by using cultured ligamentum flavum cells from six ossified samples and six control non-ossified samples. The cultured cells on each plate were disrupted in a lysis buffer containing $\beta$-mercaptoethanol, and the total RNA was purified by using RNAiso Plus (code no. 9108/9109; Takara Biomedicals, Ohtsu, Japan) and treated with DNase I (Takara Biomedicals). Reverse transcription was performed by using $1 \mu \mathrm{g}$ of total RNA, PrimeScript RT reagent Kit (RR037A; Takara Biomedicals) and a random primer. Real-time RT-PCR was performed on SYBR Premix Ex Taq II (RR081A, Takara Biomedicals) by using $1 \mu \mathrm{l}$ of the synthesized cDNA and SYBR Green PCR master mix (PE Applied Biosystems, Foster City, CA). The primer sequences used in the present study were Sox9, 5'-ACC AGT ACC CGC ACT TGC AC-3' and 5'-CGC TTC TCG CTC TCG TTC AG-3'; Runx2, 5'-CAC TGG CGC TGC AAC AAG A-3' and 5'-CAT TCC GGA GCT CAG CAG AAT AA-3'; Msx2, 5'-ATG CCA CGC CAG TGG GAT A-3' and 5'-TGC ACG CAG GGT TAG CAG AG-3'; Osterix, 5'-GCC ATT CTG GGC TTG GGT ATC-3' and 5'-GAA GCC GGA GTG CAG
GTA TCA-3'; Dlx5, 5'-TAG CTA CGC TAG CTC CTA CCA CCA G-3' and 5'-GGT TTG CCA TTC ACC ATT CTC A-3'; and AP-1, 5'-GGG AAC AGG TGG CAC AGC TTA-3' and 5'-GCA ACT GCT GCG TTA GCA TGA-3'. The target genes were amplified and analyzed in triplicate by using ABI Prism 7000 SDS software. The expression levels of the target genes were estimated relative to that of glyceraldehyde-3phosphate dehydrogenase (GAPDH).

All data were expressed as mean \pm SEM. Differences between groups were examined with the Student $t$ test. A $P$ value $<5 \%$ was considered significant.

\section{Histopathologic processing and immunohistochemical staining}

Histopathologic and immunohistochemical examinations were performed as described previously by our group [17-19,22]. The resected OLF plaque together with the surrounding ligament and ligamentous enthesis were bisected midsagittally and then fixed with $10 \%$ buffered formaldehyde for 48 hours at $4^{\circ} \mathrm{C}$, and further decalcified for 4 to 7 days at $4^{\circ} \mathrm{C}$ in $0.5 \mathrm{M}$ EDTA; and $0.5 \mathrm{M}$ Tris- $\mathrm{HCl}$ buffer at $\mathrm{pH} 7.6$, and then embedded in paraffin by using standard procedures. Serial $4-\mu \mathrm{m}$-thick sagittal sections of the OLF-ligament-enthesis complex were prepared for hematoxylin and eosin $(H \& E)$ and elastica van Gieson (EVG) staining.

For immunohistochemical staining, serial 4- $\mu$ m-thick sections were prepared from the paraffin-embedded specimens, deparaffinized with xylene, and treated with ethanol. After washing with water, the intrinsic peroxidase was blocked with $0.3 \% \mathrm{H}_{2} \mathrm{O}_{2}$-methanol solution at $20^{\circ} \mathrm{C}$ for 10 minutes and washed with phosphate-buffered saline (PBS; pH 7.4). The sections were irradiated 3 times in a polypropylene side-holder with a cap filled with PBS over a period of 5 minutes, by using a microwave oven (500 W, ER-245; Toshiba, Tokyo). The sections were then reacted with blocking solution (PBS containing carrier protein and $15 \mathrm{mM}$ sodium azide LSAB kit (Lot 00075; Dako, Glostrup, Denmark) at $20^{\circ} \mathrm{C}$ for 10 minutes. This was followed by reaction with the following primary antibodies at $4{ }^{\circ} \mathrm{C}$ overnight: rabbit polyclonal anti-Sox9 (DO406; Santa Cruz Biotechnology, Santa Cruz, CA, containing $200 \mu \mathrm{g}$ IgG in $1 \mathrm{ml}$ PBS with $<0.1 \%$ sodium azide and $0.1 \%$ gelatin), mouse monoclonal anti-Runx2 (JRH02; R\&D Systems, Minneapolis, $\mathrm{MN}$; containing $0.2 \mu \mathrm{m}$ filtered solution in PBS with $5 \%$ trehalose), rabbit polyclonal anti-Msx2 (CO404; Santa Cruz Biotechnology; containing $200 \mu \mathrm{g}$ IgG in 1 $\mathrm{ml}$ PBS with $<0.1 \%$ sodium azide and $0.1 \%$ gelatin), rabbit polyclonal anti-Osterix (20450; GeneTex, San Antonio, TX; containing $1 \mathrm{mg}$ IgG in $1 \mathrm{ml}$ PBS with $2 \%$ sucrose), rabbit polyclonal anti-Dlx5 (1; Proteintech Group, Chicago, IL; liquid solution, PBS with $0.1 \%$ 
sodium azide and $50 \%$ glycerol), and rabbit polyclonal anti-AP-1 (SH0302281; Abgent, San Diego, CA; containing $0.25 \mathrm{mg} / \mathrm{ml}$ IgG in $0.4 \mathrm{ml}$ PBS with $0.09 \% \mathrm{NaN} 3$ ) antibodies. Sections were further reacted with goat antimouse immunoglobulin antibodies and conjugated to peroxidase labeled-dextran polymer (EnVision; peroxidase, mouse, Dako) at $20^{\circ} \mathrm{C}$ for 45 minutes and then rinsed with $\mathrm{PBS}$ at $\mathrm{pH}$ 7.4. To visualize the peroxidase color reaction, sections were incubated with $\mathrm{DAB}-\mathrm{HCl}$ solution (CB090; Dojin Chemicals, Tokyo; $50 \mathrm{mg}$ dissolved in $100 \mathrm{ml}$ of $0.05 \mathrm{M}$ TRIS- $\mathrm{HCl}$ buffer at $\mathrm{pH} 7.4$ ) at $20^{\circ} \mathrm{C}$ for 10 minutes, and then washed in water. Nuclear counterstaining was carried out with hematoxylin.

Terminal deoxynucleotidyl transferase-mediated dUTPbiotin nick-end labeling (TUNEL) staining

Apoptotic cell death was assessed with the TUNEL technique. The specimens were deparaffinized and dehydrated by using standard protocols; the tissue sections $(4 \mu \mathrm{m})$ were incubated with blocking solution $(0.3 \%$ $\mathrm{H}_{2} \mathrm{O}_{2}$ in methanol) for 30 minutes at room temperature. After rinsing with $\mathrm{PBS}$ ( $\mathrm{pH} 7.2$ ), the sections were incubated for 15 minutes at $37^{\circ} \mathrm{C}$ with proteinase $\mathrm{K}$ solution $(10 \mu \mathrm{g} / \mathrm{ml}$ in $10 \mathrm{mM}$ Tris- $\mathrm{HCl}$ buffer, $\mathrm{pH} 7.4)$ and rinsed twice with PBS. TUNEL reaction mixture $(50 \mu \mathrm{l}$ enzyme solution (TdT from calf thymus in storage buffer) added to $450 \mu$ l labeled solution (nucleotide mixture in reaction buffer) and mixed well to equilibrate components) was prepared immediately before use, placed on slides $(50 \mu \mathrm{l} / \mathrm{slide})$, and incubated for 60 minutes at $37^{\circ}$ C. For the negative control, the labeled solution without terminal transferase was placed on slides $(50 \mu \mathrm{l} /$ slide $)$ instead of the TUNEL reaction mixture. These were rinsed 3 times with PBS, added to DAB substrate $(10 \mu \mathrm{l}$ $30 \% \mathrm{H}_{2} \mathrm{O}_{2}$ added to $5 \mathrm{mg} / \mathrm{ml} \mathrm{DAB}$ in $50 \mathrm{mM}$ Tris- $\mathrm{HCl}$ buffer, $\mathrm{pH}$ 7.4) and incubated for 10 minutes at room temperature. The slides were rinsed with distilled water and counterstained with methyl green (1\%) for 5 minutes. After mounting, the specimens were analyzed under light microscopy.

\section{Transmission electron microscopy}

The ligamentum flavum tissue was resected by trimming $\left(1.0 \mathrm{~mm}^{3}\right)$ and then fixed in $2.5 \%$ glutaraldehyde water solution for 2 hours. It was dehydrated with propylene oxide (Nakalai, Kyoto, Japan), and embedded in Epon 812 (Oken, Tokyo). In the final stage, 100-nm-thick ultrathin sections were prepared by using an ultramicrotome (Ultracut N; Reihert, Wien, Austria), and stained with $2 \%$ uranyl acetate (50\% ethanol solution), and observed under a transmission electron microscope $(\mathrm{H}$ 700; Hitachi, Tokyo).

\section{Results}

\section{Histopathology, TEM, and TUNEL findings}

Macroscopically, the OLF showed round, hard protrusions with a relatively smooth surface at certain regions of the dorsal surface (Figure 1c). The sagittal view showed ossification plaque that extended from the edge of the lower lamina to the upper lamina, without a clear border between the two areas, projecting ventrally into the spinal canal, accompanied by ossification of the dura mater in three $(9 \%)$ patients.

Microscopically, the control samples contained a thinlayered structure between the fiber and the laminar bone, with uniform arrangement of the fibers (Figure 2a). In OLF samples, the ossification fronts included the fibrocartilage layer, calcification front, and the calcified cartilage layer, where significant irregularities and several disruptions were prominent attributes (Figure $2 \mathrm{~b}$ ). This irregularity extended not only along the longitudinal direction of the fibers but also in other directions. In addition, a significant number of chondrocytes were present around the calcification front. Around the ossification front, osteoblasts were found, just near the ossified layer, and a gathering of infiltrative small blood vessels with mesenchymal cells (Figure 2c, d). Although elastic fibers had a regular arrangement in control samples, they showed irregular arrangement, abnormally small diameter of fragmented elastic fibers, and abundant thick bundles of collagen fibers in OLF samples (Figure $2 \mathrm{e}, \mathrm{f})$. These histopathologic findings were observed to a greater or lesser degree in all patients, being more severe in larger ossified plaques (especially in the enlarged, fused, and tuberous subtypes).

Under TEM examination, OLF samples showed the disappearance of the elastic fiber structures as well as an increase in fibrotic tissue, compared with the controls (Figure 3a, b). Matrix vesicles containing electron-dense material were also seen near the chondrocytes (Figure 3c). TUNEL-positive chondrocytes with pigmented and condensed nuclei were found around the ossification plaque, representing apoptotic cells (Figure 3d, e). In particular, TUNEL-positive chondrocytes were mostly seen in the areas close to the calcification front, especially in large ossified plaques, such as the fused and tuberous types.

\section{Cultured cells and real-time RT-PCR analysis}

A portion of the cells from the OLF samples showed spindle-shaped morphology, being arranged in several layers. In the control samples, cultured cells also showed spindle-like morphology (Figure 4a, b).

Figure 4c shows the relative mRNA expression levels of six transcriptional factors in cultured ligamentum flavum cells by using real-time RT-PCR analysis. The 

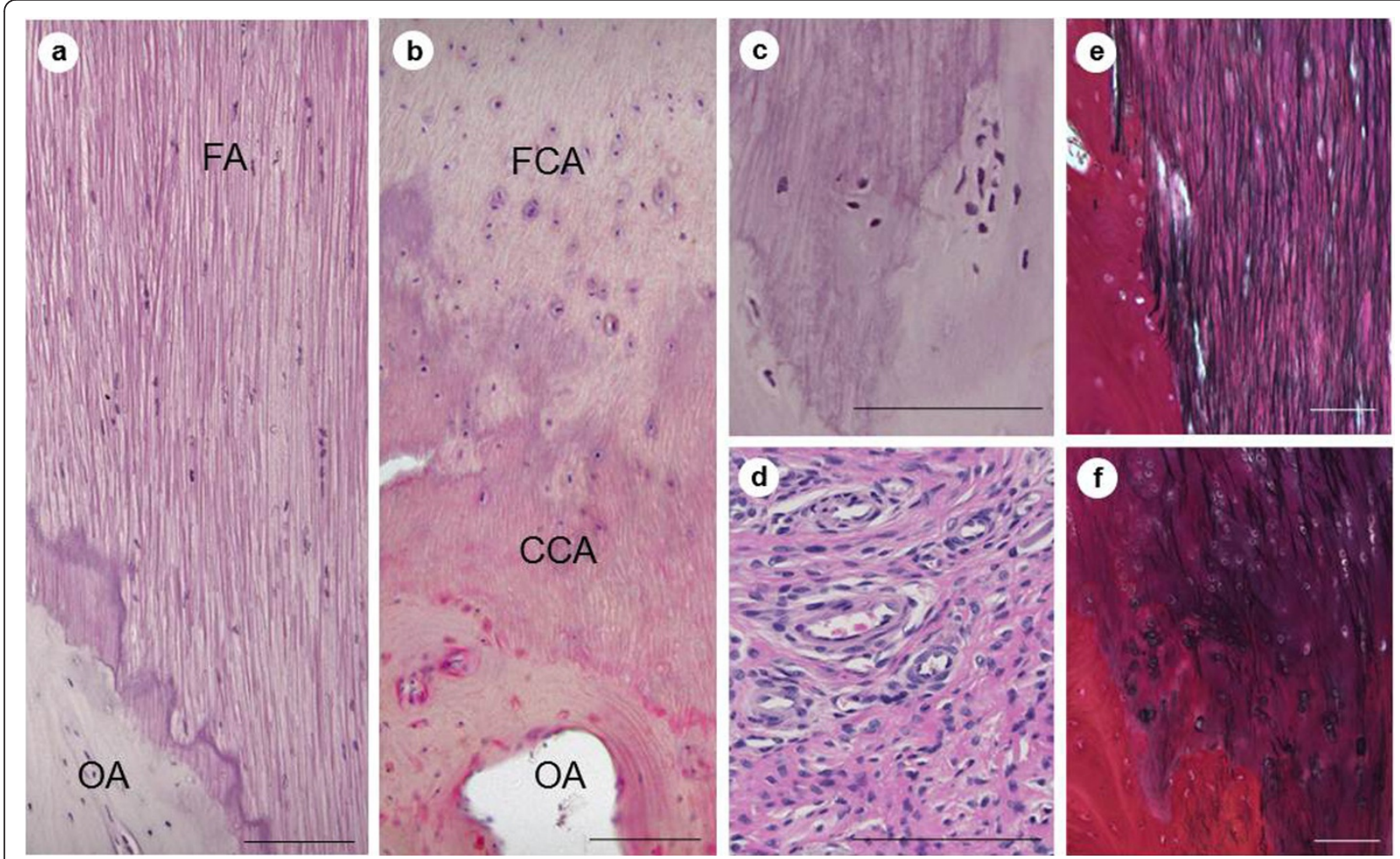

Figure 2 Histologic examination of the ossification front. Section of the control ligamentum flavum (a) showing a thin ossification front and regular arrangement of fiber bundles. In OLF samples (representative case of fused type), note the expanding ossification front, gathering many chondrocytes, and featuring an irregular of calcification front (b). In addition to the ossification front, note the presence of osteoblasts as well as small blood cells with mesenchymal cells $(\mathbf{c}, \mathbf{d})$. In the EVG image, elastic fibers exhibit a regular arrangement (e), whereas the OLF samples contained irregular, fragmented fibers or no elastic fibers (f). (a-d) H\&E; (e, f) EVG staining. CCA, calcified cartilage area; EVG, Elastica van Gieson; FA, fiber area; FCA, fibrocartilage area; OA, ossified area; OLF, ossification of the ligamentum flavum. Scale bar $=100 \mu \mathrm{m}$.

mRNA expression levels (relative to the control sample) in the OLF sample were $2.7 \pm 0.05$ for Sox $9,1.7 \pm 0.1$ for Runx2, $2.2 \pm 0.2$ for Msx2, $1.2 \pm 0.9$ for Osterix, 1.0 \pm 0.9 for Dlx5, and $1.9 \pm 0.2$ for AP- 1 . The relative mRNA expression levels of Sox9, Runx2, Msx2, and AP1 in OLF samples were significantly higher than those in the control group $(P<0.05$, each). However, the mRNA expression levels of Osterix and Dlx5 were not significantly different from the control.

\section{Immunohistochemical findings}

In 23 of 31 OLF patients, the chondrocytes present in the ossification front were immunopositive for Sox9; the immunoreactivity was strictly limited to proliferating chondrocytes in the fibrocartilage area, whereas the hypertrophic chondrocytes close to the calcification front were negative for Sox9 (Figure 5a). Conversely, Sox9 expression was significant in mesenchymal cells present around the ossification front, where the ligamentous matrix showed degenerative changes in these patients. Runx 2 expression was evident in 20 of 31 cases and localized in proliferating chondrocytes and hypertrophic chondrocytes (Figure 5b). Immunopositivity for Msx2 was noted in 24 of 31 cases and localized in proliferating chondrocytes, and in particular, the mesenchymal cells near the ossification front were strongly positive for Msx2 (Figure 5c). Positive immunostaining for Osterix was noted in 16 of 31 cases and localized in chondrocytes present in the calcified cartilage layer and fibrocartilage layer. Furthermore, numerous Osterix-positive hypertrophic chondrocytes were seen around the calcification front (Figure 6a). Immunostaining for Dlx 5 was significant in 12 of 31 cases, and that for AP-1 was in 14 of 31 cases in hypertrophic chondrocytes in the calcified cartilage area (Figure 6b, c). The immunohistochemical expression of these factors is summarized in Additional files 1 and 2.

\section{Discussion}

Ligamentum flavum is a longitudinally arranged twolayered structure lining the posterior aspect of the spinal canal and functionally allows flexibility and stabilization of the spine [23]. The normal ligament is highly elastic, based on the large proportion of elastic fibers, 

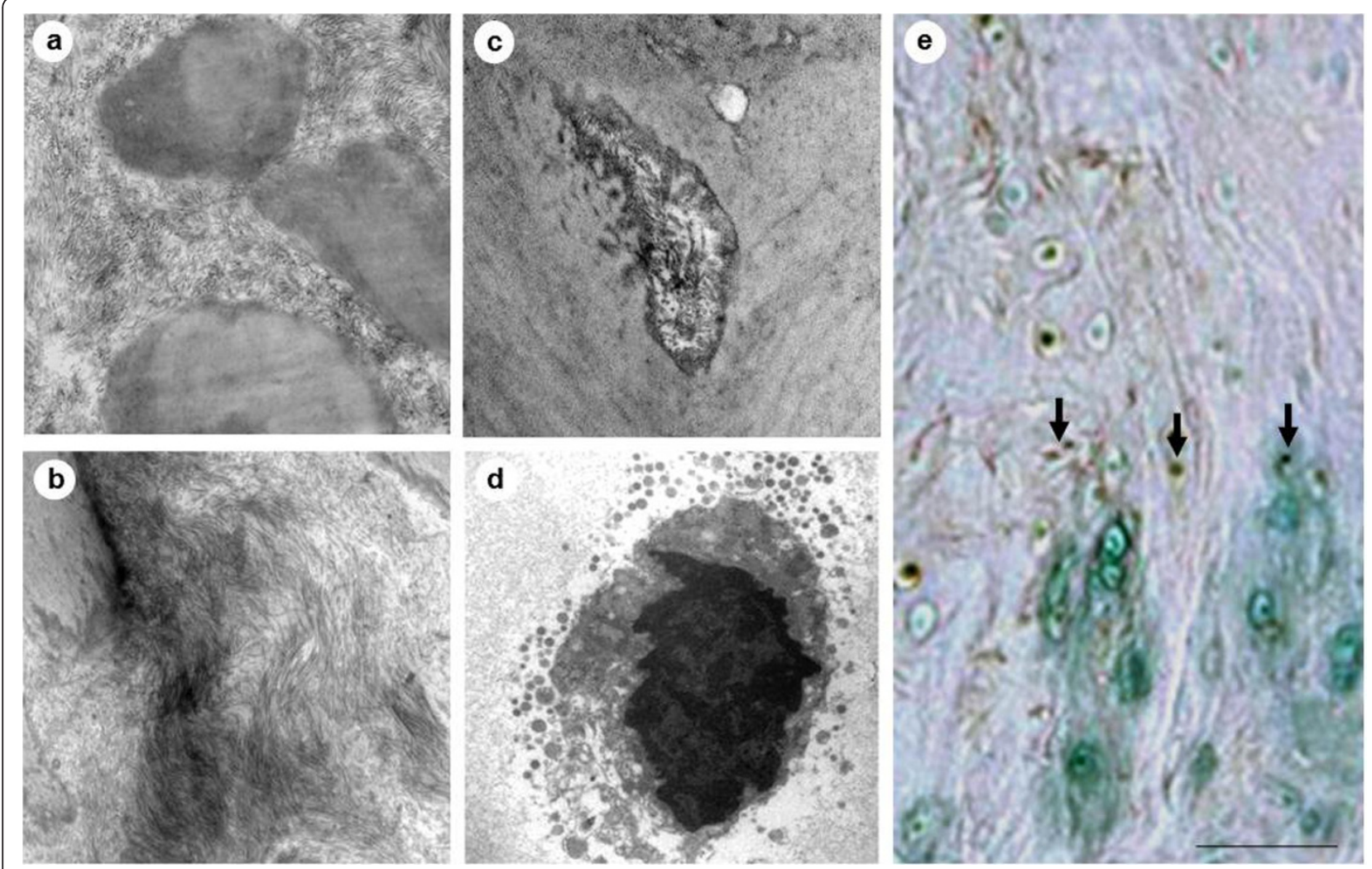

Figure 3 TEM examination and TUNEL staining of the ossification front. The typical structure of the elastic fibers had disappeared with an increase in the number of collagen fibers (a: control, b: OLF). Note the presence of matrix vesicles containing electron-dense material (c) and also the presence of pigmented chondrocytes (d) near the ossified layer ( $\mathbf{a}$, $\mathbf{b}$ : magnification $\times 1,000$, $\mathbf{c}$; magnification $\times 4,000$, $\mathbf{d}$; magnification $\times 2000$ ). Note the presence of TUNEL-positive chondrocytes near the ossified layer (arrow) (e, scale bar $=100 \mu \mathrm{m})$. OLF: ossification of the ligamentum flavum; TEM: transmission electron microscopy; TUNEL: terminal deoxynucleotidyl transferase-mediated dUTP-biotin nick endlabeling.

accounting for $60 \%$ to $70 \%$ of the dry weight [24], with little blood flow. However, the cross-sectional area and viscoelasticity of the elastic fibers diminish as part of age-related changes or systemic hormonal imbalance, although the elastic fiber bundles retain their normal longitudinal arrangement [25-27]. The pathologic process of degeneration that affects the ligamentum flavum is characterized by disorganization of the elastic fibers with irregular arrangement, a decrease in the number of these fibers, and an increase in collagen fibers [28-30].

In the ossification front of OLF, fiber bundles of the ligament showed disorganization of the elastic fibers and an abundance of collagen fibers. We reported previously that the initial degenerative changes in the ligamentum flavum include reduction in the diameter of elastic fibers together with irregular arrangement and their rupture [25]. The elastic fiber bundles showed gradual fragmentation and extinction, probably because of the action of proteases such as elastase and chymotrypsin [31]. We consider that such matrix changes are important in the development of the ossified plaque, particularly in the fused and tuberous subtypes of OLF, compared with the lateral, extended, and enlarged subtypes [19].

Previous studies examined various aspects of the OLF. Genetic studies identified abnormalities in COL6A2 and COL11A1 genes, on chromosome 21, in patients with ossification of the spinal ligaments $[14,32]$. The expressions of these genes may explain why this pathologic process occurs mainly in East Asian countries. Conversely, the ligamentum flavum is persistently subjected to repetitive variable degrees of tensile stress along its longitudinal axis, and mechanical stress influences the cell biologic properties, such as expression of cytokines and/or transcriptional factors [12,33,34]. Our results showed overexpression of Sox9, Runx2, Msx2, and AP-1 mRNAs in cells cultured from OLF compared with the control samples. Conversely, the mRNA expression levels of Osterix and Dlx5 were not different from the control, although the protein expression of all these factors was positive at the cells gathering in the ossification front in vivo environment. Considered together with the previously mentioned studies, we speculate that the 

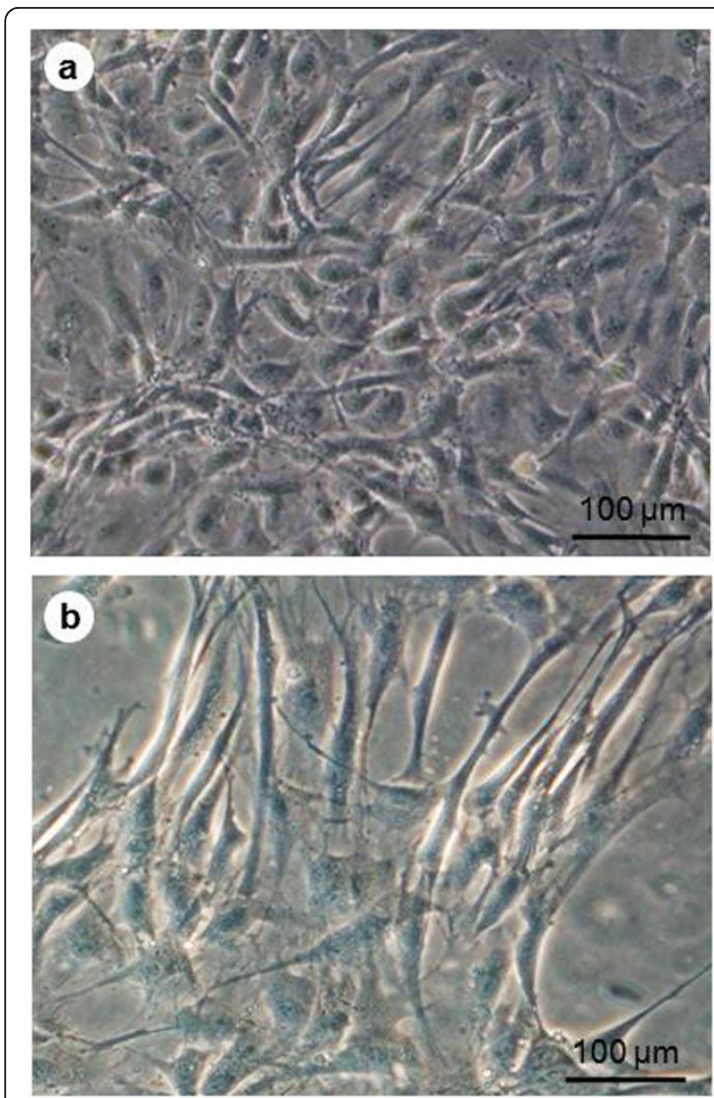

\section{(C)}

(relative expression)

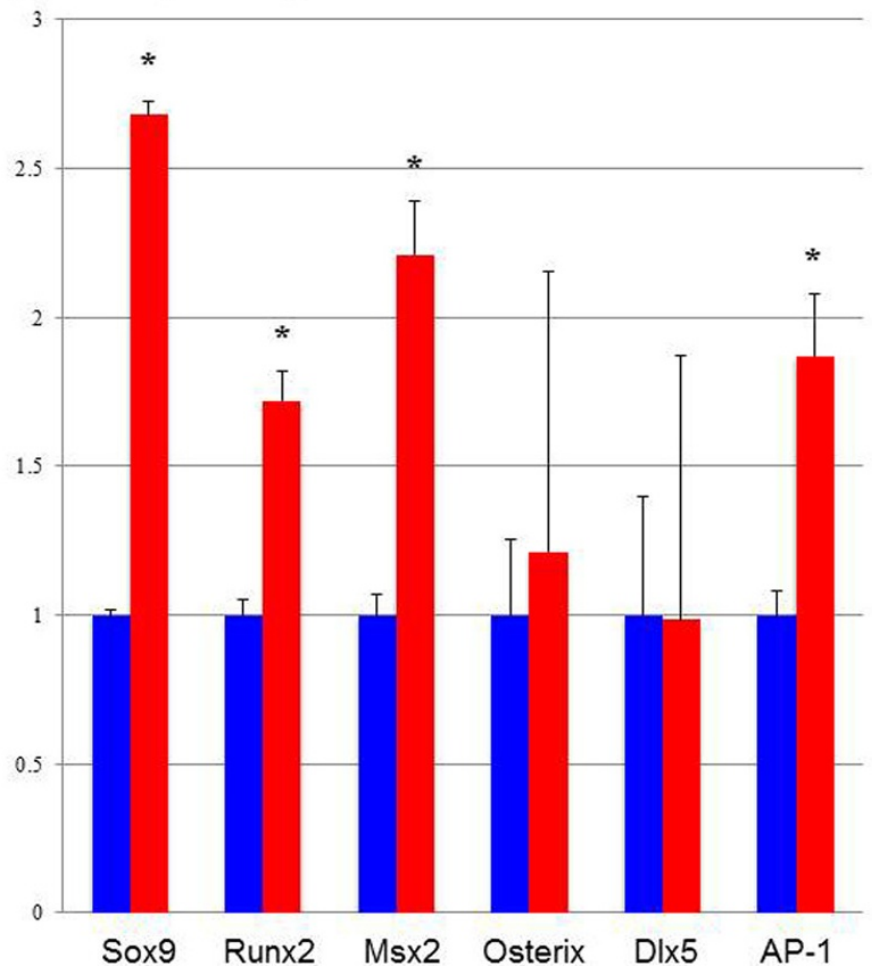

Figure 4 Morphologic findings of cultured cells and relative expression levels of mRNA of transcriptional factors. Cultured cells in OLF (a) and control (b) showed spindle shape (scale bar $=100 \mu \mathrm{m}$ ). RT-PCR analysis of the ossified and nonossified cultured ligament cells showed that the mRNA expression levels of Sox9, Runx2, Msx2, and AP-1 in OLF were significantly different from those of the control (c). Data are expressed as mean \pm SEM values of six samples each. Differences between the two groups were examined with the Student $t$ test. ${ }^{*} P<0.05$, compared with the control. mRNA, messenger RNA; OLF, ossification of the ligamentum flavum; RT-PCR, reverse transcription-polymerase chain reaction.

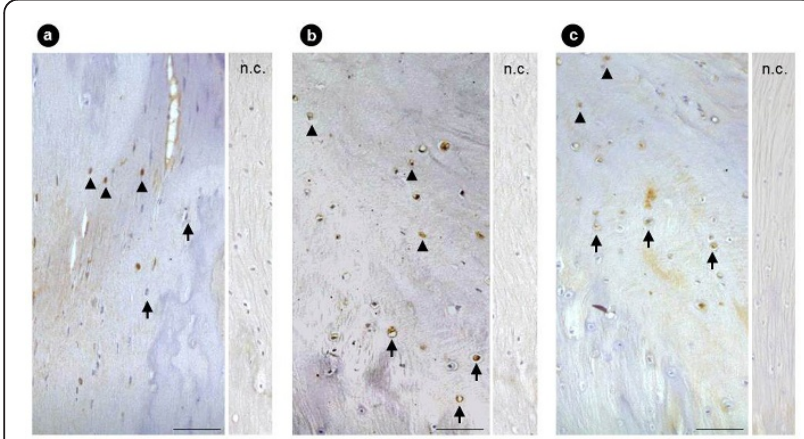

Figure 5 Immunostaining for Sox9, Runx2, and Msx2 of the OLF. Sox9 (a) was expressed in proliferating chondrocytes. Runx2 (b) was expressed in hypertrophic chondrocytes. Msx2 (c) was expressed in proliferating chondrocytes (scale bar $=100 \mu$ m; n.c., negative control; black arrow, hypertrophic chondrocytes; black arrowheads, proliferating chondrocytes).

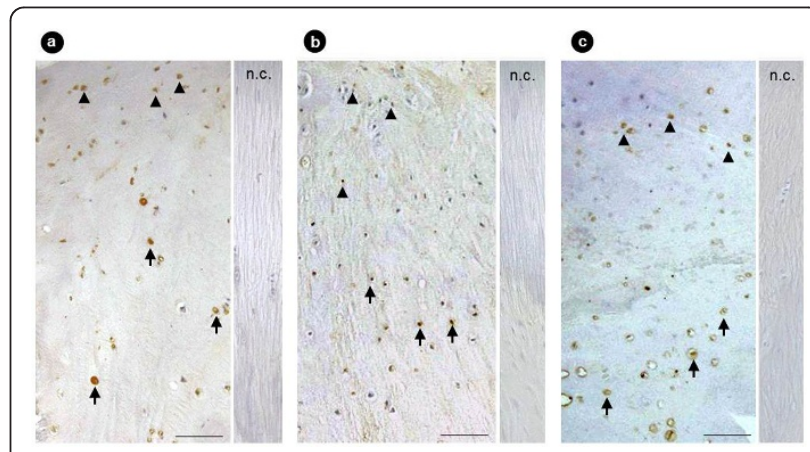

Figure 6 Immunostaining for Osterix, DIx5, and AP-1 in the OLF. Osterix (a), DIx5 (b), and AP-1 (c) were strongly positive in hypertrophic chondrocytes (scale bar $=100 \mu \mathrm{m}$; n.c., negative control; black arrow, hypertrophic chondrocytes; black arrowheads, proliferating chondrocytes). OLF, ossification of the ligamentum flavum. 
observed changes are due to the diversity of genetic background as well as spinal mechanical stress, degenerative matrix changes, and/or other yet-unknown factors that influence the expression levels of these transcriptional factors.

Several studies $[16,35,36]$ concluded that the process of ossification of the spinal ligament involves enchondral ossification and clustering of abnormal fibrocartilage or cartilaginous cells, which results in the development of the ossified plaque. Numerous chondrocytes were present, especially around the calcification front, although no such chondrocytes were found in the normal ligamentum flavum [17,25,31]. Yahia et al. [37] suggested that the metaplastic chondrocytes in the ligamentum flavum are derived from mesenchymal cells or fibroblastlike cells. In this regard, our study indicates the involvement of certain transcriptional factors in this process. Sox9 is known to promote chondrocyte differentiation, but to prevent hypertrophic changes [38]. Runx2 promotes the differentiation of premature chondrocytes to hypertrophic chondrocytes [39]. In contrast, Msx2 induces differentiation of premature mesenchymal cells and sometimes prevents the maturation of chondrocytes [40]. In the normal ligamentum flavum, these factors might regulate chondrocyte differentiation, preserving homeostasis; however, overexpression of these factors in the OLF violates the regulation of chondrogenesis and differentiation of mesenchymal or fibroblast-like cells to mature chondrocytes in a complex autocrine/paracrine manner.

The maturation of osteoblastic cells and bone formation correlate closely with stromal expansion and neovascularization. We reported previously that hypertrophic chondrocytes around the calcification front regulate angiogenesis by secreting various growth factors, such as vascular endothelial growth factor [19]. Neovascularization promotes infiltration of mesenchymal cells and alters matrix mineralization, particularly in the area of the ossification front. However, many TUNEL-positive hypertrophic chondrocytes were noted in the ossified front, especially around the calcification front. It is not clear whether the chemical change in the matrix induces apoptosis of the hypertrophic chondrocytes or if these cells themselves undergo programmed cell death triggered by biochemical alteration of the chondroid matrix secondary to the degeneration of the ligamentum flavum, or whether apoptosis was induced by the ossified plaque and/or matrix vesicles. We suggest that apoptosis of the hypertrophic chondrocytes induces secondary infiltration of osteoblastic cells through the expression of transcriptional factors such as Runx2, Osterix, Dlx5, and AP-1 [41-43].

\section{Conclusions}

Our study showed significant matrix degeneration in the ossification front of OLF and the presence of several ossification fronts between the ossified plaque and nonossified fiber area. Chondrocyte differentiation was evident in the ossification front and while accumulation of chondrocytes was evident around the calcification front. We suspect that chondrocyte differentiation under the influence of transcriptional factors plays a key role in the ossification process.

\section{Additional material}

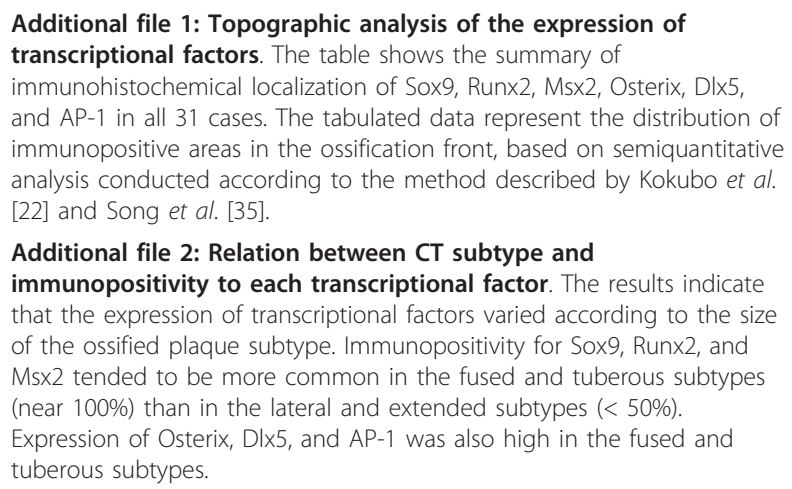

\section{Abbreviations}

CCA: calcified cartilage area; CT: computed tomography; DIx5: distal-less homeobox 5; EDTA: ethylene diaminetetraacetic acid; EVG: Elastica van Gieson; FA: fiber area; FCA: fibrocartilage area; GAPDH: glyceraldehyde-3phosphate dehydrogenase; H\&E: hematoxylin and eosin; MRI: magnetic resonance imaging; Msx2: muscle segment homeobox 2; n.c.: negative control; OA: ossified area; OLF: ossification of the ligamentum flavum; PBS: phosphate-buffered saline; RT-PCR: reverse transcription-polymerase chain reaction; Runx2: runt-related transcription factor 2; Sox9: Sry-type highmobility group box 9; TEM: transmission electron microscopy; TUNEL: terminal deoxynucleotidyl transferase-mediated dUTP-biotin nick-end labeling.

\section{Acknowledgements}

This work was supported in part by grants (2004 2011) to HB and KU from the Investigation Committee on Ossification of the Spinal Ligaments, the Public Health Bureau of the Japanese Ministry of Labor, Health and Welfare; TY, from The International Orthopaedics and Traumatology Foundation (2011), and by grants-in-aid (B18390411, B19791023, C21591895, C21791389, B22390287, and Young-B22791366) to HB, HN, TY, and KU for General Scientific Research of the Japanese Ministry of Education, Science and Culture.

\section{Author details}

${ }^{1}$ Department of Orthopaedics and Rehabilitation Medicine, Faculty of Medical Sciences, Fukui University, Eiheiji, Fukui 910-1193, Japan.

${ }^{2}$ Department of Orthopedic Surgery, Sir Run Run Shaw Hospital, Zhejiang University School of Medicine, Hangzhou 310016, People's Republic of China ${ }^{3}$ Servicio de Neurocirugia, Hospital Nacional Rosales, Universidad de El Salvador, San Salvador 106-8000, El Salvador. ${ }^{4}$ Department of Spinal Surgery, The First Affiliated Hospital, Sun Yat-Sen University School of Medicine, Guangzhou 510080, People's Republic of China. 


\section{Authors' contributions}

$H B$, who did not participate in the histopathologic and immunohistochemical assessments, performed the surgeries. KU and TY (principal authors), together with $\mathrm{HC}, \mathrm{DS}, \mathrm{AG}, \mathrm{AY}$, and $\mathrm{KC}$, were blinded to the surgical findings and were responsible for all histopathologic investigations. HN and SK examined all data. All authors participated in the elaboration of this document, approving the final version of this manuscript for publication.

\section{Competing interests}

The authors declare that they have no competing interests.

Received: 2 June 2010 Revised: 13 May 2011

Accepted: 13 September 2011 Published: 13 September 2011

\section{References}

1. Epstein NE: Ossification of the yellow ligament and spondylosis and/or ossification of the posterior longitudinal ligament of the thoracic and lumbar spine. J Spinal Disord 1999, 12:250-256.

2. Inamasu J, Guiot BH: A review of factors predictive of surgical outcome for ossification of the ligamentum flavum of the thoracic spine. $J$ Neurosurg Spine 2006, 5:133-139.

3. Resnick D: Calcification and ossification of the posterior spinal ligaments and tissues. In Diagnosis of Bone and Joint Disorders.. 2 edition. Edited by: Resnick D, Niwayama G. Philadelphia: WB Saunders; 1988:1603-1615.

4. Kim TJ, Kim TH, Jun JB, Joo KB, Uhm WS: Prevalence of ossification of posterior longitudinal ligament in patients with ankylosing spondylitis. J Rheumatol 2007, 34:2460-2462

5. Vera CL, Cure JK, Naso WB, Gelven PL, Worsham F, Roof BF, Resnick D, Salinas CF, Gross JA, Pacult A: Paraplegia due to ossification of ligamenta flava in X-linked hypophosphatemia: a case report. Spine 1997, 22:710-715.

6. Aizawa T, Sato T, Tanaka Y, Ozawa H, Hoshikawa T, Ishii Y, Morozumi N, Ishibashi K, Kasama F, Hyodo H, Murakami E, Nishihira T, Kokubun S: Thoracic myelopathy in Japan: epidemiological retrospective study in Miyagi Prefecture during 15 years. Tohoku J Exp Med 2006, 210:199-208.

7. Guo JJ, Luk KD, Karppinen J, Yang H, Cheung KM: Prevalence, distribution, and morphology of ossification of the ligamentum flavum: a population study of one thousand seven hundred thirty-six magnetic resonance imaging scans. Spine 2010, 35:51-56.

8. Xu R, Sciubba DM, Gokaslan ZL, Bydon A: Ossification of the ligamentum flavum in a Caucasian man. J Neurosurg Spine 2008, 9:427-437.

9. Baba H, Maezawa Y, Imura S, Kawahara N, Tomita K: Spinal cord evoked potential monitoring for cervical and thoracic compressive myelopathy. Paraplegia 1996, 34:100-106.

10. Uchida K, Nakajima H, Yayama T, Kobayashi S, Shimada S, Tsuchida T, Okazawa H, Mwaka E, Baba H: High-resolution magnetic resonance imaging and ${ }^{18} \mathrm{FDG}$-PET findings of the cervical spinal cord before and after decompressive surgery in patients with compressive myelopathy. Spine 2009, 34:1185-1191

11. Baba H, Furusawa N, Fukuda M, Maezawa Y, Imura S, Kawahara N, Nakahashi K, Tomita K: Potential role of streptozotocin in enhancing ossification of the posterior longitudinal ligament of the cervical spine in the hereditary spinal hyperostotic mouse (twy/twy). Eur J Histochem 1997, 41:191-202.

12. Tsukamoto N, Maeda T, Miura H, Jingushi S, Hosokawa A, Harimaya K, Higaki H, Kurata K, Iwamoto Y: Repetitive tensile stress to rat caudal vertebrae inducing cartilage formation in the spinal ligaments: a possible role of mechanical stress in the development of ossification of the spinal ligaments. J Neurosurg Spine 2006, 5:234-242.

13. Kawaguchi $H$, Kurokawa T, Hoshino $Y$, Kawahara H, Ogata E, Matsumoto T: Immunohistochemical demonstration of bone morphogenetic protein-2 and transforming growth factor- $\beta$ in the ossification of the posterior longitudinal ligament of the cervical spine. Spine 1992, 17:S33-S36.

14. Tanaka T, Ikari K, Furushima K, Okada A, Tanaka H, Furukawa K, Yoshida K, Ikeda T, Ikegawa S, Hunt SC, Takeda J, Toh S, Harata S, Nakajima T, Inoue I: Genomewide linkage and linkage disequilibrium analyses identify COL6A1, on chromosome 21 , as the locus for ossification of the posterior longitudinal ligament of the spine. Am J Hum Genet 2003, 73:812-822.
15. Wang Z, Li XD, Li MQ, Wang QP: Changes in basic metabolic elements associated with the degeneration and ossification of ligamenta flava. $J$ Spinal Cord Med 2008, 31:279-284.

16. Miyasaka K, Kaneda K, Sato S, Iwasaki Y, Abe S, Takei H, Tsuru M, Tashiro K, Abe H, Fujioka Y: Myelopathy due to ossification or calcification of the ligamentum flavum: radiologic and histologic evaluations. AJNR Am J Neuroradiol 1983, 4:629-632.

17. Furusawa N, Baba H, Imura S, Fukuda M: Characteristics and mechanism of the ossification of posterior longitudinal ligament in the tip-toe walking Yoshimura (twy) mouse. Eur J Histochem 1996, 40:199-210.

18. Sato R, Uchida K, Kobayashi S, Yayama T, Kokubo Y, Nakajima H, Takamura T, Bangirana A, Itoh H, Baba H: Ossification of the posterior longitudinal ligament of the cervical spine: histopathological findings around the calcification and ossification front. J Neurosurg Spine 2007, 7:174-183

19. Yayama T, Uchida K, Kobayashi S, Kokubo Y, Sato R, Nakajima H, Takamura T, Bangirana A, Itoh H, Baba H: Thoracic ossification of the human ligamentum flavum: histopathological and immunohistochemical findings around the ossified lesion. J Neurosurg Spine 2007, 7:184-193.

20. Sato T, Kokubun S, Tanaka Y, Ishii Y: Thoracic myelopathy in the Japanese: epidemiological and clinical observations on the cases in Miyagi Prefecture. Tohoku J Exp Med 1998, 184:1-11.

21. Miyakoshi N, Shimada Y, Suzuki T, Hongo M, Kasukawa Y, Okada K, Itoi E: Factors related to long-term outcome after decompressive surgery for ossification of the ligamentum flavum of the thoracic spine. I Neurosurg 2003, 99:251-256.

22. Kokubo Y, Kobayashi S, Uchida K, Noriki S, Imamura Y, Furusawa N, Yayama T, Kakuyama M, Nakajima H, Fujimoto M, Negoro K, Fukuda M, Baba H: Herniated and spondylotic intervertebral discs of the human cervical spine: histological and immunohistochemical observations. Acta Histochem Cytochem 2004, 37:109-117.

23. Olszewski AD, Yaszemski MJ, White AA: The anatomy of the human lumbar ligamentum flavum: new observations and their surgical importance. Spine 1996, 21:2307-2312.

24. Yong-Hing K, Reilly J, Kirkaldy-Willis WH: The ligamentum flavum. Spine 1976, 1:226-234.

25. Yayama T, Baba H, Furusawa N, Kobayashi S, Uchida K, Kokubo Y, Noriki S, Imamura Y, Fukuda M: Pathogenesis of calcium crystal deposition in the ligamentum flavum correlates with lumbar spinal canal stenosis. Clin Exp Rheumatol 2005, 23:637-643.

26. Blacher J, Dabire H, Pomies JP, Safar ME, Stimpel M: Long-term cardiovascular effects of high "osteoprotective" dose levels of 17 betaestradiol in spontaneously hypertensive rats. Cardiovasc Drugs Ther 2000 14:303-307.

27. Kashiwagi K: [Histological changes of the lumbar ligamentum flavum with age]. J Jpn Orthop Assoc 1993, 67:221-229, Article in Japanese.

28. Yoshida M, Shima K, Taniguchi Y, Tamaki T, Tanaka T: Hypertrophied ligamentum flavum in lumbar spinal canal stenosis: pathogenesis and morphologic and immunohistochemical observation. Spine 1992, 17:1353-1360

29. Postacchini F, Gumina S, Cinotti G, Perugia D, DeMartino C: Ligamenta flava in lumbar disc herniation and spinal stenosis: light and electron microscopic morphology. Spine 1994, 19:917-922.

30. Schräder PK, Grob D, Rahn BA, Cordey J, Dvorak J: Histology of the ligamentum flavum in patients with degenerative lumbar spinal stenosis. Eur Spine J 1999, 8:323-328.

31. Furusawa N, Baba H, Maezawa Y, Uchida K, Wada M, Imura S, Fukuda M: Calcium crystal deposition in the ligamentum flavum of the lumbar spine. Clin Exp Rheumatol 1997, 15:641-647.

32. Horikoshi T, Maeda K, Kawaguchi Y, Chiba K, Mori K, Koshizuka Y, Hirabayashi S, Sugimori K, Matsumoto M, Kawaguchi H, Takahashi M, Inoue H, Kimura T, Matsusue Y, Inoue I, Baba H, Nakamura K, Ikegawa S: A large-scale genetic association study of ossification of the posterior longitudinal ligament of the spine. Hum Genet 2006, 119:611-616.

33. Iwasawa T, Iwasaki K, Sawada T, Okada A, Ueyama K, Motomura S, Harata S, Inoue I, Toh S, Furukawa KI: Pathophysiological role of endothelin in ectopic ossification of human spinal ligaments induced by mechanical stress. Calcif Tissue Int 2006, 79:422-430.

34. Iwasaki K, Furukawa KI, Tanno M, Kusumi T, Ueyama K, Tanaka M, Kudo H, Toh S, Harata S, Motomura S: Uni-axial cyclic stretch induces Cbfa1 expression in spinal ligament cells derived from patients with 
ossification of the posterior longitudinal ligament. Calcif Tissue Int 2004, 74:448-457.

35. Song J, Mizuno J, Hashizume Y, Nakagawa H: Immunohistochemistry of symptomatic hypertrophy of the posterior longitudinal ligament with special reference to ligamentous ossification. Spinal Cord 2006, 44:576-581.

36. Yamazaki M, Goto S, Kobayashi Y, Terakado A, Moriya H: Bone cells from spinal hyperostotic mouse (twy/twy) maintain elevated levels of collagen production in vitro. J Bone Miner Metab 1994, 12:57-63.

37. Yahia H, Drouin G, Maurais G, Garzon S, Rivard CH: Degeneration of the human lumbar spine ligaments: an ultrastructural study. Pathol Res Pract 1989, 184:369-375

38. Ikeda T, Kawaguchi H, Kamekura S, Ogata N, Mori Y, Nakamura K, Ikegawa S, Chung UI: Distinct roles of Sox5, Sox6, and Sox9 in different stages of chondrogenic differentiation. J Bone Miner Metab 2005, 23:337-340.

39. Fujita T, Azuma Y, Fukuyama R, Hattori Y, Yoshida C, Koida M, Ogita K, Komori T: Runx2 induces osteoblast and chondrocyte differentiation and enhances their migration by coupling with P13K-Akt signaling. J Cell Biol 2004, 166:85-95.

40. Yoshizawa T, Takizawa F, lizawa F, Ishibashi O, Kawashima H, Matsuda A, Endo N, Kawashima H: Homeobox protein Msx2 acts as a molecular defense mechanism for preventing ossification in ligament fibroblasts. Mol Cell Biol 2004, 24:3460-3472.

41. Komori T: Regulation of osteoblast differentiation by transcription factors. J Cell Biochem 2006, 99:1233-1239.

42. Samee N, Geoffroy V, Marty C, Schiltz C, Vieux-Rochas M, Levi G, de Vernejoul MC: Dlx5, a positive regulator of osteoblastogenesis, is essential for osteoblast-osteoclast coupling. Am J Pathol 2008, 173:773-780.

43. Gao Y, Jheon A, Nourkeyhani H, Kobayashi H, Ganss B: Molecular cloning, structure, expression, and chromosomal localization of the human Osterix (SP7) gene. Gene 2004, 341:101-110.

doi:10.1186/ar3458

Cite this article as: Uchida et al.: Ossification process involving the human thoracic ligamentum flavum: role of transcription factors. Arthritis Research \& Therapy 2011 13:R144.

\section{Submit your next manuscript to BioMed Central and take full advantage of:}

- Convenient online submission

- Thorough peer review

- No space constraints or color figure charges

- Immediate publication on acceptance

- Inclusion in PubMed, CAS, Scopus and Google Scholar

- Research which is freely available for redistribution

Submit your manuscript at www.biomedcentral.com/submit 